\section{Association of TIR Domain Containing Adaptor Protein (TIRAP) Gene Variant rs8177400 with Susceptibility and Clinical Outcomes of Plasmodium Infection in the Pakistani Population}

\author{
Asima Rani ${ }^{1, *}$, Syed Kashif Nawaz ${ }^{2}$ and Muhammad Arshad ${ }^{3}$ \\ ${ }^{1}$ Department of Zoology, University of Sargodha, Sargodha \\ ${ }^{2}$ Department of Biological Sciences, Sub Campus Mianwali, University of \\ Sargodha, Mianwali \\ ${ }^{3}$ University of Education, Lower Mall Campus, Lahore
}

\begin{abstract}
A B S T R A C T
This case control study was aimed to determine the role of rs8177400 polymorphism in TIR-domaincontaining-adaptor-protein gene in malaria susceptibility and clinical outcomes upon P. falciparum and P. vivax exposure. Blood samples of 228 malaria patients and 226 healthy controls were selected from the local population. Malarial samples were divided in to complicated malaria $(\mathrm{N}=89)$ and mild malaria $(\mathrm{N}=139)$ groups according to WHO criteria. Malarial groups were further divided into $P$. vivax and $P$. falciparum groups based on the Plasmodium species responsible for the infection. Allele specific PCR was employed for the amplification of rs 8177400 polymorphism. Results of genotyping were confirmed via PCR-RFLP strategy. Presence of GG genotype decreases the susceptibility of malaria (OR: 0.544 , CI: 0.331 to $0.894, \mathrm{p}=0.053$ ), mild malaria (OR: 0.472 , CI: 0.274 to $0.815, \mathrm{p}=0.024$ ) and $P$. vivax infection (OR: 0.362 , CI: 0.211 to $0.622, \mathrm{p}=0.000$ ). AG heterozygosity increased the susceptibility of malaria (OR: 1.835, CI: 1.117 to $3.013, \mathrm{p}=0.053$ ), mild malaria (OR: 2.115 , CI: 1.226 to $3.649, \mathrm{p}=0.024$ ) and $P$. vivax infection (OR: $2.758, \mathrm{CI}: 1.607$ to $4.732, \mathrm{p}=0.000$ ). GG genotype decreased the risk of mild malaria due to $P$. vivax infection (OR: $0.312,95 \%$ CI: 0.170 to $0.572, \mathrm{p}=0.000$ ). AG genotype increased the chances of mild malaria due to $P$. vivax infection (OR: $3.205,95 \%$ CI: 1.747 to $5.878, \mathrm{p}=0.000$ ). $P$. vivax infection may develop mild malaria symptoms in AG carriers of rs 8177400 polymorphism in the Pakistani population.
\end{abstract}

\begin{tabular}{l} 
Article Information \\
Received 17 February 2019 \\
Revised 02 April 2019 \\
Accepted 18 May 2019 \\
Available online 20 January 2020 \\
Authors' Contribution \\
\hline AR and SKN designed research, \\
performed research work, analyzed \\
data, and wrote the paper. MA \\
supervised the research work and \\
helped in preparation of manuscript. \\
Key words \\
Malaria, Plasmodium, rs8177400, \\
TIRAP, Pakistani population.
\end{tabular}

\section{INTRODUCTION}

$\mathrm{M}$ alaria remains an important health issue of the tropical and subtropical countries since decades (Onyishi et al., 2018). World Health Organization (WHO) estimated worldwide incidence of 219 million cases and 435000 deaths due to malaria in 2017. Malaria develops from the pathogenic attack of a protozoan from genus Plasmodium. It is transmitted via bite of an infected Anopheles mosquito. Five species of Plasmodium can infect and be transmitted by humans; $P$. malariae, $P$. ovale, $P$. knowlesi, $P$. falciparum and $P$. vivax. Clinical outcomes of malaria vary among infected individuals and are classified into severe/ complicated malaria and mild/uncomplicated malaria (WHO, 2018). Pakistan shares $22 \%$ of the total regional malaria burden of Eastern Mediterranean Region with

\footnotetext{
Corresponding author: primer.snp@gmail.com 0030-9923/2020/0002-0593 \$ 9.00/0

Copyright 2020 Zoological Society of Pakistan
}

956280 estimated malaria cases in 2017 (WHO, 2018). Sixty percent of the population of Pakistan lives in malaria endemic areas (Khattak et al., 2013), whereas, travel transmissions in non-endemic areas is also possible. Two species of Plasmodium were reported as main agents responsible for malaria; $P$. vivax and P. falciparum with a prevalence of $78 \%$ and $21 \%$, respectively. WHO listed Pakistan among the list of five countries which shares about $82 \%$ of the estimated P. vivax malaria cases in 2017 (WHO, 2018).

Since long P. falciparum infection was considered as the most virulent infection responsible for severe malaria and malarial deaths. However, severe malarial complications and consequences with $P$. vivax infections have also been reported (Jain et al., 2008). Immune system renders resistance to various infectious agents including Plasmodium parasite. Immune system specifically detects pathogen associated molecular patterns (PAMPs) from various pathogens via toll like receptors (TLRs) (Pandey et al., 2018). Different TLRs have different specificities 
for various pathogens, however TLR2 and TLR4 were reported to have role in Plasmodium recognition (Gowda, 2007; Krishnegowda et al., 2005). Signaling of TLRs occurs through Toll/IL1R (TIR) domain. TLR4 and TLR2 after activation mediates its intracellular signaling via an additional adaptor protein MyD88-adapter-like (MAL) also known as TIRAP (O'Neill et al., 2003). This results in the activation of NF- $\kappa$ B pathway, which culminates in the upregulation of various inflammatory cytokines (Armant and Fenton, 2002). The inflammatory cytokines have anti-parasitic properties and helps in parasitic clearance. Though, heightened inflammatory response results in severe clinical outcomes of disease. Genetic factors of host, particularly those involved in immune regulation, were reported to influence the clinical outcomes of malaria. Different genetic polymorphisms were found in association with the susceptibility/resistance to malaria infection (Driss et al., 2011). Enhanced inflammatory response has been reported as the chief cause of complicated malaria causing tissue injury and systemic inflammation. On the other hand, diminished inflammatory response cannot effectively clears the parasitic load (Sun et al., 2012).

TIRAP is a decisive adaptor protein involved in the intracellular signaling of TLR2/TLR4. It is the most polymorphic among all adapter proteins with at least eight single nucleotide polymorphisms (SNPs) in the coding region. Genetic polymorphisms in the TIRAP gene can influence the susceptibility/resistance to various diseases. TIRAP is a cytoplasmic protein having 221 amino acids. Gene for TIRAP is located at chromosome 11q24.2. SNPs altering the function of TIRAP regulates the inflammatory response and perform pivotal role in different infectious diseases. An important SNP rs8177374 has been reported in association with inflammatory diseases, tuberculosis, bacteremia, pneumococcal disease and malaria in some ethnic populations (Khor et al., 2007; Castiblanco et al., 2008). Our findings also reported association of this polymorphism with malaria in the Pakistani population (Rani et al., 2017). Another non-synonymous SNP in TIRAP, rs8177400 causes nucleotide change of guanine (G) to adenine (A) at position 722. This variation causes aspartic acid to asparagine (D96N) change in the TIR domain of TIRAP. rs8177400 variation affects TIRAP functioning, due to this variant TIRAP becomes unable to recruit its signaling partner MyD88 to cell membrane. It has been considered as a functionally important variant of TIRAP. This hypomorphic variant has been observed with decreased signaling and activation of NF- $\mathrm{B}$ (George et al., 2010). Therefore, rs 8177400 variant results in diminished production of inflammatory cytokines. This polymorphism was found associated with tuberculosis in the Chinese population (Zhang et al., 2011). However, association of this variant with malaria and other diseases has not been studied so far.

Considering the functional importance of rs 8177400 polymorphism of TIRAP gene, a case control study was designed to explore the role of a rare polymorphism rs8177400 in association with Plasmodium infection and clinical outcomes of malaria in the Pakistani population.

\section{MATERIALS AND METHODS}

All procedures of the study followed declaration of Helsinki. Study procedure was approved by the advanced research and study board University of Sargodha. Ethical Committee, University of Sargodha approved the competency of this study. All contributors of this study were conversant about the study and approved permission for using their DNA and related information for research purpose.

\section{Sampling}

Blood samples of 516 individuals were collected, out of which 454 were amplified successfully and thus selected for study. Patients' blood was collected during September 2013 to September 2015 from different hospitals of Punjab, Pakistan. Venous blood $(5 \mathrm{ml})$ from each individual was collected in EDTA coated vacutainer (BD, USA) and stored at $-20^{\circ} \mathrm{C}$ till analysis. Study comprises of 228 samples of malaria patients and 226 samples of healthy volunteers.

Malaria samples were confirmed based on presence or absence of Plasmodium in blood sample. For the detection of Plasmodium kit method (ImuMed, China) was used. For Plasmodium detection, 5ul of blood sample was dropped in the sample well (S) followed by the addition of 3 drops of lysis buffer in well (B) of the test cassette. Results were calculated after $30 \mathrm{~min}$. If line appeared on control and $P v$, then sample contains $P$. vivax. If line appeared on control and $P f$, then sample contains $P$. falciparum. If line just appeared on control, then sample contains no Plasmodium species. Malaria samples were categorized into two groups, $P$. falciparum and $P$. vivax.

Malaria samples were also grouped into complicated malaria and mild malaria groups according to the criteria mentioned by WHO (2018). Complicated malaria patients had severe anemia $(\mathrm{Ht}<20 \%, \mathrm{Hb}<6 \mathrm{~g} / \mathrm{dl})$, neurological problems (prostration, lethargy), hyperparasitemia corresponding to $>5 \%$ parasitemia, gastrointestinal disturbances, oliguria, acidosis with respiratory distress, hypoglycemia (serum glucose corresponding to $40 \mathrm{mg} / \mathrm{dl}$ ), cardiovascular shock, jaundice and diffuse hemorrhages. All other malaria samples were placed in mild malaria group.

Gender matched healthy volunteers were selected from the local population as controls, based on the absence of history of Plasmodium infection. 
Genotyping of rs 8177400

Genomic DNA was isolated from blood samples by following the standard protocol of blood DNA isolation kit (Vivantis, Cat\# GF-BD-100). DNA was detected using $0.8 \%$ agarose gel. Allele specific PCR strategy was employed for the amplification of targeted sequence. Two forward primers, F1 5'GCCACAGTGAGGAAG3', F2 5'GCCACAGTGAGGAAA3' and one reverse primer R 5' GCAGCATCTGGTACTT 3' were designed for amplification of rs8177400 polymorphism. They were synthesized from Invitrogen, USA through local agent. For genotyping, reaction mixture of 50ul was prepared using PCR master mix of vivantis (product \# PL1202). PCR includes initial denaturation step $\left(94^{\circ} \mathrm{C}\right)$, followed by denaturation cycles $\left(30\right.$ cycles at $94^{\circ} \mathrm{C}$ for $\left.30 \mathrm{sec}\right)$, annealing ( 30 cycles at $48.9^{\circ} \mathrm{C}$ for $30 \mathrm{sec}$ ), extension (30 cycles at $68^{\circ} \mathrm{C}$ for $\left.30 \mathrm{sec}\right)$ and final extension step $\left(68^{\circ} \mathrm{C}\right.$ for $12 \mathrm{~min}$ ). Detection of PCR products were performed using $2 \%$ agarose gel, under a UV transilluminator. PCR product of $216 \mathrm{bp}$ with F1 primer and F2 primer corresponds to GG and AA genotype, respectively. AG genotype was detected based on the PCR product of 216bp with both F1 and F2 primers. DNA marker (Invitrogen, cat. no: 10416-014) was run in the agarose gel and product size (216bp) was detected by comparing with the DNA marker.

For the confirmation of results of allele specific PCR, PCR restriction fragment length polymorphism (PCRRFLP) was performed on few samples. For genotyping of rs8177400 a Forward primer: 5' GAGGCCCAACTCCCC3' and a Reverse primer: 5' CCСТTCTCСCTCCTG3' were synthesized from Invitrogen, USA through local agent. PCR was performed with same steps as mentioned above with the difference of annealing temperature i.e. $49.3^{\circ} \mathrm{C}$. PCR product of $568 \mathrm{bp}$ was produced and confirmed by comparing with the DNA marker (Invitrogen, cat. no: 10416-014) that was run in the agarose gel. The PCR product was restriction digested with the restriction enzyme MobII (Cat \# ER0821, Thermo Fisher scientific). The reaction mixture was allowed to incubate over night at $37^{\circ} \mathrm{C}$. Restriction fragments were detected on 3\% agarose gel. Appearance of a single band of $568 \mathrm{bp}$ corresponds to AA genotype. GG homozygous condition corresponds to the presence of two bands, 191bp and 377bp. Appearance of all three bands indicates the AG heterozygous condition.

\section{Statistical analysis}

Categorical variables were compared using a Chisquare $\left(\chi^{2}\right)$ test. Continuous variables were compared via student's t test. Hardy Weinberg Equilibrium (HWE) estimation, allele frequencies, genetic frequencies and differences in frequencies were analyzed through $\chi 2$. HWE estimation was performed using an online calculator (Rodriguez et al., 2009). Association between malaria groups and genotypes was examined via $\chi^{2} \cdot \chi^{2}$ test and other nonparametric tests were applied by SPSS software, version 18 for Windows (SPSS Inc., Chicago Illinois, USA). Odds ratio (OR) estimation was performed considering the control group as reference. An online calculator was used for Odds ratios estimation (Bland and Altman, 2000).

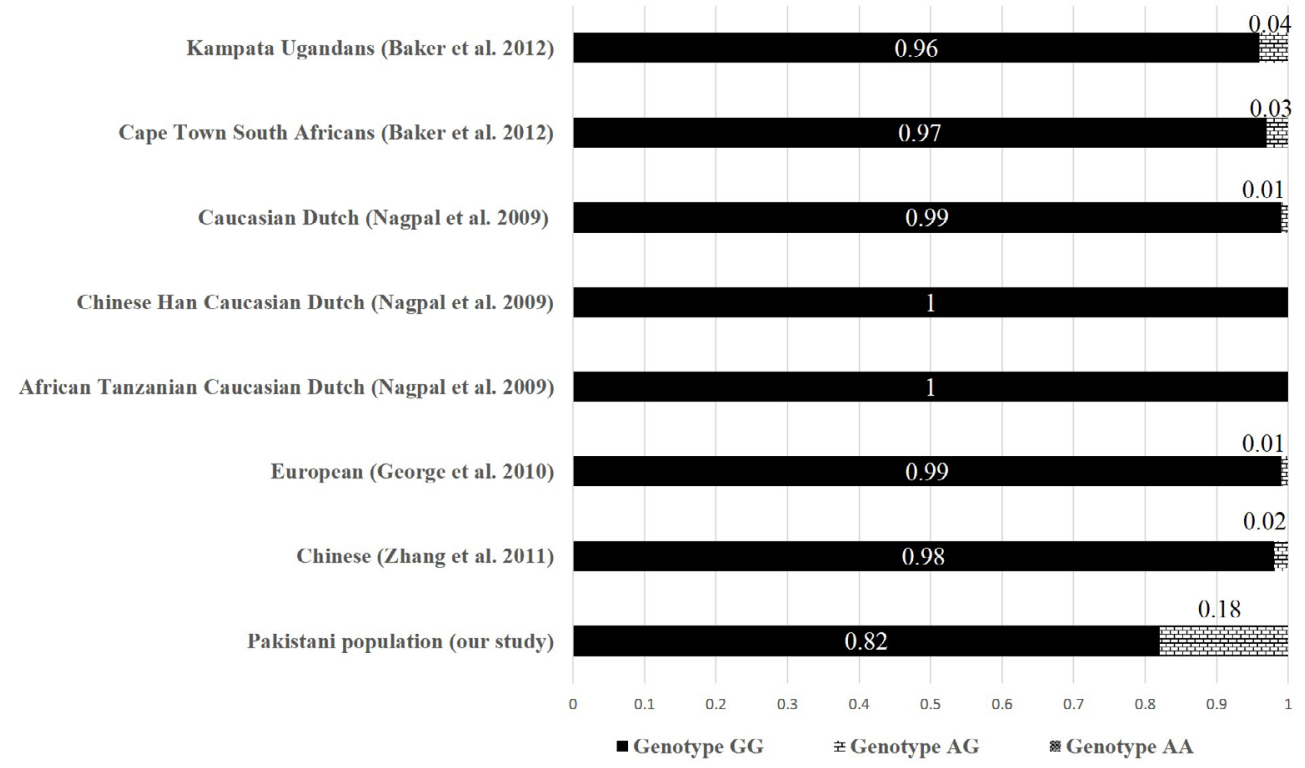

Fig. 1. Comparison of genotypic frequencies of rs 8177400 polymorphism in various populations. 


\section{RESULTS}

This study involved 454 samples; 226 of malaria patients and 228 of control group. Malaria and control groups didn't differ on the basis of age $(p=0.64)$ and gender $(\mathrm{p}=0.70)$. Malaria group was divided in to complicated malaria $(\mathrm{N}=89)$ and mild malaria group $(\mathrm{N}=139)$. Complicated malaria group includes $\mathrm{N}=40 P$. falciparum infected and $\mathrm{N}=49 P$. vivax infected samples. Mild malaria group comprises $\mathrm{N}=60 P$. falciparum infected and $\mathrm{N}=79 P$. vivax infected samples (Table I).

Table I.- Characteristics of study population.

\begin{tabular}{lccc}
\hline Parameters & $\begin{array}{c}\text { Malaria } \\
\text { patients } \\
(\mathbf{n = 2 2 8})\end{array}$ & $\begin{array}{c}\text { Control } \\
(\mathbf{n = 2 2 6})\end{array}$ & p-value \\
& $\begin{array}{c}22.67 \pm \\
13.64\end{array}$ & $\begin{array}{c}22.24 \pm \\
2.75\end{array}$ & 0.64 \\
\hline Age in years (Mean $\pm \mathrm{SD})$ & $53.5 \%$ & $55.3 \%$ & 0.70 \\
& & & \\
Gender (Male\%) & 40 & 0.00 & $\mathrm{ND}$ \\
Complicated malaria (n=89) & 49 & 0.00 & $\mathrm{ND}$ \\
$\begin{array}{l}\text { P. falciparum infected group } \\
\text { P. vivax infected group }\end{array}$ & & & \\
Mild malaria (n=139) & 60 & 0.00 & $\mathrm{ND}$ \\
$\begin{array}{l}\text { P. falciparum infected group } \\
\text { P. vivax infected group }\end{array}$ & 79 & 0.00 & $\mathrm{ND}$ \\
\hline
\end{tabular}

$\mathrm{ND}$, not determined. Student $\mathrm{t}$ test was performed for comparison of means, $\chi 2$ test was performed for the comparison of groups.

\section{Genotypes and alleles frequencies}

All groups stood in HWE ( $>0.05)$ except total samples which depict deviation from HWE $(p<0.05)$. The minor allele A has a frequency of 0.09 in the studied population. No sample with AA homozygosity was observed (Table II). Figure 1 presents the comparison of genotypic frequencies of rs8177400 polymorphism in various populations. None of the studied populations have AA homozygous condition.

Association of rs8177400 with malaria groups based on symptoms and type of parasite

GG and AG genotypes were found in association with malaria $(\mathrm{p}=0.05)$, mild malaria $(\mathrm{p}=0.024)$ and $P$. vivax infection $(\mathrm{p}=0.00)$ (Table III). GG genotype was found to decrease the chances of malaria (OR: 0.544, 95\% CI: 0.331 to 0.894 ), mild malaria (OR: 0.472 , 95\% CI: 0.274 to 0.815 ) and $P$. vivax infection (OR: $0.362,95 \%$ CI: 0.211 to 0.622 ). Whereas, AG genotype increased the risk of malaria (OR: $1.835,95 \% \mathrm{CI}: 1.117$ to 3.013 ). AG genotype was found more frequent in mild malaria group (OR: $2.115,95 \%$ CI: 1.226 to 3.649 ). AG genotype increased 2.758 times the risk of $P$. vivax infection (OR: 2.758, 95\% CI: 1.607 to 4.732 ). G allele was found to have protective role in $P$. vivax infection (OR: $0.437,95 \% \mathrm{CI}$ : 0.216 to $0.883, \mathrm{p}=0.018$ ). A allele increased 2.287 times the risk of $P$. vivax infection (OR: $2.287,95 \% \mathrm{CI}$ : 1.131 to 4.626, $\mathrm{p}=0.018$ ) (Table III).

Association of rs8177400 with symptom-based malaria groups due to Plasmodium exposure

GG genotype decreased the risk of mild malaria due to $P$. vivax infection (OR: $0.312,95 \% \mathrm{CI}: 0.170$ to 0.572 , $\mathrm{p}=0.000)$. AG genotype is more frequent among mild malaria patients due to $P$. vivax infection (OR: $3.205,95 \%$ CI: 1.747 to $5.878, \mathrm{p}=0.000)$. G allele decreased the risk of mild malaria due to $P$. vivax infection (OR: $0.386,95 \% \mathrm{CI}$ : 0.176 to $0.845, \mathrm{p}=0.014$ ) whereas, A allele increased the risk of mild malaria due to $P$. vivax infection (OR: 2.585 , 95\% CI: 1.182 to 5.652, $\mathrm{p}=0.014$ ) (Table IV).

Table II.- Genotypes and alleles frequencies of rs8177400 in various groups with results of HWE.

\begin{tabular}{|c|c|c|c|c|c|c|c|c|}
\hline \multirow[t]{2}{*}{ S No } & \multirow[t]{2}{*}{ Groups } & & \multicolumn{3}{|c|}{ Genotypes } & \multicolumn{2}{|c|}{ Alleles } & \multirow[t]{2}{*}{ HWE (p) } \\
\hline & & & $\begin{array}{c}\text { GG } \\
\text { n (Freq) }\end{array}$ & $\begin{array}{c}\text { AA } \\
\text { n (Freq) }\end{array}$ & $\begin{array}{c}\text { AG } \\
\text { n (Freq) }\end{array}$ & $\begin{array}{c}\mathbf{G} \\
\mathrm{n} \text { (Freq) }\end{array}$ & $\begin{array}{c}\text { A } \\
\text { n (Freq) }\end{array}$ & \\
\hline \multirow[t]{2}{*}{1} & $\mathrm{SM}(\mathrm{n}=89)$ & P. falciparum $(\mathrm{n}=40)$ & $36(0.9)$ & 00 & $04(0.1)$ & $38(0.95)$ & $02(0.05)$ & $0.11(0.740)$ \\
\hline & & P. vivax $(\mathrm{n}=49)$ & $37(0.76)$ & 00 & $12(0.24)$ & $43(0.88)$ & $06(0.12)$ & $0.95(0.329)$ \\
\hline \multirow[t]{2}{*}{2} & MM (n=139) & P. falciparum $(\mathrm{n}=60)$ & $52(0.87)$ & 00 & $08(0.13)$ & $56(0.93)$ & $04(0.07)$ & $0.31(0.577)$ \\
\hline & & P. vivax $(\mathrm{n}=79)$ & $53(0.67)$ & 00 & $26(0.33)$ & $66(0.84)$ & $13(0.16)$ & $3.06(0.080)$ \\
\hline 3 & \multicolumn{2}{|c|}{ Total malarial samples $(\mathrm{n}=228)$} & $178(0.78)$ & 00 & $50(0.22)$ & $203(0.89)$ & $25(0.11)$ & $3.46(0.062)$ \\
\hline 4 & \multicolumn{2}{|c|}{ Control $(\mathrm{n}=226)$} & $196(0.87)$ & 00 & $30(0.13)$ & $210(0.93)$ & $16(0.07)$ & $1.14(0.285)$ \\
\hline 5 & \multicolumn{2}{|c|}{ Total samples $(n=454)[$ Malaria + Control $]$} & $374(0.82)$ & 00 & $80(0.18)$ & $413(0.91)$ & $41(0.09)$ & $4.24(0.039)$ \\
\hline
\end{tabular}

Malaria, malarial patients; Control, healthy individuals; SM, severe malaria; MM, mild malaria; HWE, Hardy Weinberg equilibrium; p, statistical P value; n, number of individuals; Freq, frequency. 
Table III.- Association of rs8177400 polymorphism with malaria groups based on symptoms and type of parasite.

\begin{tabular}{|c|c|c|c|c|c|c|c|c|}
\hline \multirow[t]{2}{*}{ Groups } & & \multicolumn{3}{|c|}{ Genotypes } & \multirow{2}{*}{$\chi^{2}(\mathbf{p})$} & \multicolumn{2}{|c|}{ Alleles } & \multirow[t]{2}{*}{$\chi^{2}(p)$} \\
\hline & & GG & $\mathbf{A A}$ & AG & & $\mathbf{G}$ & $\mathbf{A}$ & \\
\hline \multirow[t]{3}{*}{ Malaria } & Malaria $(n=228$ & 178 & 00 & 50 & \multirow{3}{*}{$\begin{array}{l}5.858 \\
(0.053)\end{array}$} & 203 & 25 & \multirow{3}{*}{$\begin{array}{l}2.085 \\
(0.148)\end{array}$} \\
\hline & Control $(n=226)$ & 196 & 00 & 30 & & 210 & 16 & \\
\hline & OR $(95 \% \mathrm{CI})$ & $\begin{array}{c}0.544 \\
(0.331-0.894)\end{array}$ & $\mathrm{NaN}$ & $\begin{array}{c}1.835 \\
(1.117-3.013)\end{array}$ & & $\begin{array}{c}0.618 \\
(0.320-1.192)\end{array}$ & $\begin{array}{c}1.616 \\
(0.838-3.116)\end{array}$ & \\
\hline \multirow{6}{*}{$\begin{array}{l}\text { Symptom } \\
\text { based groups }\end{array}$} & $\mathrm{CM}(\mathrm{n}=89)$ & 73 & 00 & 16 & \multirow{3}{*}{$\begin{array}{c}1.133 \\
(0.567)\end{array}$} & 81 & 08 & \multirow{3}{*}{$\begin{array}{c}0.331 \\
(0.565)\end{array}$} \\
\hline & Control $(n=226)$ & 196 & 00 & 30 & & 210 & 16 & \\
\hline & OR $(95 \% \mathrm{CI})$ & $\begin{array}{c}0.698 \\
(0.359-1.356)\end{array}$ & $\mathrm{NaN}$ & $\begin{array}{c}1.432 \\
(0.737-2.780)\end{array}$ & & $\begin{array}{c}0.771 \\
(0.317-1.872)\end{array}$ & $\begin{array}{c}1.296 \\
(0.534-3.145)\end{array}$ & \\
\hline & MM (n=139) & 105 & 00 & 34 & \multirow{3}{*}{$\begin{array}{l}7.448 \\
(0.024)\end{array}$} & 122 & 17 & \multirow{3}{*}{$\begin{array}{l}2.776 \\
(0.095)\end{array}$} \\
\hline & Control $(\mathrm{n}=226)$ & 196 & 00 & 30 & & 210 & 16 & \\
\hline & OR $(95 \% \mathrm{CI})$ & $\begin{array}{c}0.472 \\
(0.274-0.815)\end{array}$ & $\mathrm{NaN}$ & $\begin{array}{c}2.115 \\
(1.226-3.649)\end{array}$ & & $\begin{array}{c}0.546 \\
(0.266-1.121)\end{array}$ & $\begin{array}{c}1.828 \\
(0.891-3.750)\end{array}$ & \\
\hline \multirow{6}{*}{$\begin{array}{l}\text { Plasmodium } \\
\text { infection-based } \\
\text { groups }\end{array}$} & P. $f(\mathrm{n}=100)$ & 88 & 00 & 12 & \multirow{3}{*}{$\begin{array}{c}0.1 \\
(0.951)\end{array}$} & 94 & 06 & \multirow{3}{*}{$\begin{array}{c}0.128 \\
(0.720)\end{array}$} \\
\hline & Control $(\mathrm{n}=226)$ & 196 & 00 & 30 & & 210 & 16 & \\
\hline & OR $(95 \% \mathrm{CI})$ & $\begin{array}{c}1.122 \\
(0.549-2.294)\end{array}$ & $\mathrm{NaN}$ & $\begin{array}{c}0.890 \\
(0.435-1.821)\end{array}$ & & $\begin{array}{c}1.193 \\
(0.452-3.146)\end{array}$ & $\begin{array}{c}0.837 \\
(0.317-2.208)\end{array}$ & \\
\hline & P. v & 90 & 00 & 38 & \multirow{3}{*}{$\begin{array}{l}14.185 \\
(0.000)\end{array}$} & 109 & 19 & \multirow{3}{*}{$\begin{array}{c}5.529 \\
(0.018)\end{array}$} \\
\hline & Control $(n=226)$ & 196 & 00 & 30 & & 210 & 16 & \\
\hline & OR (95\%CI) & $\begin{array}{c}0.362 \\
(0.211-0.622)\end{array}$ & $\mathrm{NaN}$ & $\begin{array}{c}2.758 \\
(1.607-4.732)\end{array}$ & & $\begin{array}{c}0.437 \\
(0.216-0.883)\end{array}$ & $\begin{array}{c}2.287 \\
(1.131-4.626)\end{array}$ & \\
\hline
\end{tabular}

Control, healthy volunteers; CM, complicated malaria; MM, mild malaria; P.f, P. falciparum; P.v, P. vivax; OR, odds ratios; CI, confidence interval; $\chi^{2}$, Chi square; $p$, statistical $\mathrm{P}$ value; $\mathrm{n}$, number of individuals; NaN, not a number. Odds ratio (OR) estimation was performed considering the control group as reference.

Table IV.- Association of rs8177400 with symptom-based malaria groups due to Plasmodium exposure.

\begin{tabular}{|c|c|c|c|c|c|c|c|c|}
\hline \multirow[t]{2}{*}{ Groups } & & \multicolumn{3}{|c|}{ Genotypes } & \multirow[t]{2}{*}{$\chi^{2}(\mathbf{p})$} & \multicolumn{2}{|c|}{ Alleles } & \multirow[t]{2}{*}{$\chi^{2}(\mathbf{p})$} \\
\hline & & GG & $\mathbf{A A}$ & AG & & $\mathbf{G}$ & $\mathbf{A}$ & \\
\hline \multirow{6}{*}{$\begin{array}{l}\text { Complicated } \\
\text { malaria }\end{array}$} & P. $f(\mathrm{n}=40)$ & 36 & 00 & 04 & \multirow{3}{*}{$\begin{array}{c}0.327 \\
(0.849)\end{array}$} & 38 & 02 & \multirow{3}{*}{$\begin{array}{c}0.233 \\
(0.629)\end{array}$} \\
\hline & Control $(n=226)$ & 196 & 00 & 30 & & 210 & 16 & \\
\hline & OR (95\%CI) & $\begin{array}{c}1.377 \\
(0.457-4.147)\end{array}$ & $\mathrm{NaN}$ & $\begin{array}{c}0.725 \\
(0.241-2.185)\end{array}$ & & $\begin{array}{c}1.447 \\
(0.319-6.553)\end{array}$ & $\begin{array}{c}0.690 \\
(0.152-3.127)\end{array}$ & \\
\hline & P. $v(\mathrm{n}=49)$ & 37 & 00 & 12 & \multirow{3}{*}{$\begin{array}{c}3.914 \\
(0.141)\end{array}$} & 43 & 06 & \multirow{3}{*}{$\begin{array}{c}1.46 \\
(0.226)\end{array}$} \\
\hline & Control $(n=226)$ & 196 & 00 & 30 & & 210 & 16 & \\
\hline & OR (95\%CI) & $\begin{array}{c}0.471 \\
(0.221-1.005)\end{array}$ & $\mathrm{NaN}$ & $\begin{array}{c}2.118 \\
(0.994-4.512)\end{array}$ & & $\begin{array}{c}0.546 \\
(0.202-1.475)\end{array}$ & $\begin{array}{c}1.831 \\
(0.677-4.948)\end{array}$ & \\
\hline \multirow[t]{6}{*}{ Mild malaria } & P. $f(\mathrm{n}=60)$ & 52 & 00 & 08 & \multirow[t]{3}{*}{$0(1)$} & 56 & 04 & \multirow{3}{*}{$\begin{array}{c}0.012 \\
(0.912)\end{array}$} \\
\hline & Control $(n=226)$ & 196 & 00 & 30 & & 210 & 16 & \\
\hline & OR $(95 \% \mathrm{CI})$ & $\begin{array}{c}0.994 \\
(0.430-2.299)\end{array}$ & $\mathrm{NaN}$ & $\begin{array}{c}1.005 \\
(0.434-2.322)\end{array}$ & & $\begin{array}{c}1.066 \\
(0.343-3.317)\end{array}$ & $\begin{array}{c}0.937 \\
(0.301-2.915)\end{array}$ & \\
\hline & P. $v(\mathrm{n}=79)$ & 53 & 00 & 26 & \multirow{3}{*}{$\begin{array}{l}15.059 \\
(0.000)\end{array}$} & 66 & 13 & \multirow{3}{*}{$\begin{array}{c}5.981 \\
(0.014)\end{array}$} \\
\hline & Control $(n=226)$ & 196 & 00 & 30 & & 210 & 16 & \\
\hline & OR (95\%CI) & $\begin{array}{c}0.312 \\
(0.170-0.572)\end{array}$ & $\mathrm{NaN}$ & $\begin{array}{c}3.205 \\
(1.747-5.878)\end{array}$ & & $\begin{array}{c}0.386 \\
(0.176-0.845)\end{array}$ & $\begin{array}{c}2.585 \\
(1.182-5.652)\end{array}$ & \\
\hline
\end{tabular}

For abbreviations and statistical details, see Table III. 


\section{DISCUSSION}

Innate immune system defend host against the invading pathogens (Hato and Dagher, 2015). Immune cells specifically detect pathogens via TLRs. TLRs specifically identify PAMPs from pathogens. Among various TLRs, TLR2 and TLR4 were known to have role in the detection of Plasmodium parasite (Gowda, 2007). TLR4 specifically detects LPS from Plasmodium and initiates the intracellular signaling (Krishnegowda et al., 2005). MAL/TIRAP is an important adaptor protein in the downstream signaling of MyD88 dependent signaling pathway of TLR2 and TLR4 (Fitzgerald et al., 2001; Horng et al., 2001). TIRAP works as a linking adaptor between TLR2/TLR4 and sorting adaptor MyD88 (Kagan and Medzhitov, 2006). This signaling cascade finishes in the activation of transcription factors like NF- $\kappa \mathrm{B}$, IRF5 and AP-1, which upregulates the release of pro-inflammatory cytokines (Vogel et al., 2003). Theses cytokines help host in parasitic clearance. However, increased level of inflammatory cytokines can cause systemic inflammation (Sun et al., 2012). On the other hand, reduced pro-inflammatory response is unable to clear the parasitic load and may develop severe disease outcomes.

Genetic variations in the TLRs and their downstream signaling partners may alter the host response towards invading pathogens and thus clinical outcomes of diseases. Disease progression into complicated or mild clinical outcomes depends on the host immune response (Corr and O'Neill, 2009). Non-synonymous SNPs in TLRs and related adaptor proteins has been evaluated in association with different infectious and inflammatory diseases. SNPs in adaptor proteins may mark influential effects on progression of infections (Hawn et al., 2006; Wurfel et al., 2008).

TIRAP is the most polymorphic adaptor protein with at least eight non-synonymous SNPs, and thus considered as an important candidate for evaluation of genetic variation in relation to TLR2/TLR4 signaling (Nagpal et al., 2009). An important SNP rs8177374, in the TIRAP gene has been studied in association with various diseases. Khor et al. (2007) reported protective effect of heterozygous genotype of rs8177374 against bacteremia, pneumococcal disease, tuberculosis and malaria. Association of this SNP has been studied with malaria in Gambian (Nejentsev et al., 2008), Iranian Balochi (Zakeri et al., 2011), Indian (Panda et al., 2016) and Brundian population (Esposito et al., 2012). Protective effects of heterozygous forms of rs8177374 against malaria were also reported in the Pakistani population (Rani et al., 2017).

rs8177400 (G/A) is another important nonsynonymous SNP in the TIRAP gene. This polymorphism causes amino acid substitution of aspartic acid with Asparagine at position 96. Molecular studies of George et al. (2010) reported rs8177400 polymorphism as a defective mutation with reduced NF- $\mathrm{BB}$ activation. Nagpal et al. (2009) reported the inability of TIRAP with rs8177400 polymorphism, to bind with the MyD88. This results in defective signaling upon TLR2/TLR4 activation. They considered rs 8177400 as a hypomorphic variation with impaired cytokine production. These studies suggested rs8177400 polymorphism as a functionally important polymorphism for immunological and epidemiological studies.

rs8177400 polymorphism has been considered as a rare mutation. Frequency of A allele was found low in all studied human populations (NCBI). Frequency of A allele was also found lower in our studied population. We didn't observe any homozygous AA individual in the studied population. This mutant homozygous form was also not found in the Chinese, European, African Tanzanian, Chinese Han, Caucasian Dutch, Cape Town South Africans and Kampala Ugandans (Fig. 1). Homozygous mutants were expected to be hypersusceptible to life threatening infections (Nagpal et al., 2009). AA homozygosity was reported to be non-functional. Absence of any individual with homozygous variant AA and low frequency of A allele was not unexpected, as the data of Nagpal et al. (2009) reported this mutation as awfully fatal. Individuals with this mutation would be extremely susceptible to infections (Nagpal et al., 2009).

This study observed the protective effects of GG genotype of rs8177400 in susceptibility of malaria, mild malaria and $P$. vivax infection. This may suggest the appropriate activation of NF- $\kappa \mathrm{B}$ pathway and release of inflammatory cytokines in the presence of GG genotype, which protects host from the parasitic attacks. AG genotype was detected as the causative genotype for malaria, mild malaria and $P$. vivax infection. As molecular evidences of George et al. (2010) and Nagpal et al. (2009) reported the inability of TIR AP with rs8177400 polymorphism, to bind with the MyD88. This results in defective signaling upon TLR2/TLR4 activation in the presence of A allele. Different clinical studies and murine models reported the important role of pro-inflammatory and anti-inflammatory cytokines in the pathogenesis of malaria. Pro-inflammatory cytokines response helps in parasitic clearance and is beneficial for the host. However, enhanced inflammatory response develops systemic inflammation causing tissue injury and complicated disease outcomes. Reduced production of pro-inflammatory cytokines can also develop deleterious effects on the host. Reduced/abandoned release of proinflammatory cytokines is unable to clear the parasitic load (Day et al., 1999). Ineffective pro-inflammatory response 
in the presence of A allele may develop malaria symptoms. However, association of AG genotype with mild malaria suggests the effective immune response yet not as effective as with GG genotype. This further supports the evidence that wild type GG genotype can elicit effective signaling and activation of NF- $\kappa \mathrm{B}$ pathway. AG genotype was also found causative in susceptibility to mild malaria upon $P$. vivax exposure. rs 8177400 polymorphism has been studied in association with some diseases. AG heterozygosity of rs8177400 polymorphism was found a causative genotype for tuberculosis in the Chinese population (Zhang et al., 2011). However, rs8177400 polymorphism didn't have any association with the susceptibility of lymphoma in the Caucasian population (George et al., 2010).

Association of rs 8177400 with mild malaria due to P. vivax exposure indicates the causative effects of $\mathrm{AG}$ genotype in susceptibility of mild malaria. This may suggest that $P$. vivax infection develops mild malaria symptoms in AG carriers of the Pakistani population. Molecular data of George et al. (2010) and Nagpal et al. (2009) reported the functional inability of TIRAP with rs8177400 polymorphism, presence of A allele indicates some survival advantage as AG genotype elicit balanced release of pro-inflammatory response. Nagpal et al. (2009) suggested that heterozygous individuals may have survival advantage in some unidentified conditions and considered it as an important polymorphism.

Despite the presence of effective medication for malaria, some infected individuals develop complicated malaria. Multidrug resistance in Plasmodium parasite and development of complicated malaria in immune compromised individuals posed difficulties in malaria control. Previous studies suggested that the infecting species of Plasmodium decides the clinical outcomes of malaria. $P$. falciparum was considered as the most virulent parasite, responsible for complicated malaria and even malaria related deaths. Now it has been established that $P$. vivax infection can also develop severe malarial outcomes (Jain et al., 2008). Development of complicated malaria in some subjects posited the importance of host immune response instead of the type of invading parasite (Rani et al., 2017). We didn't observe any association between rs8177400 and complicated malaria. Considering George at al. (2010) and Nagpal et al. (2009) observations, this may be suggested that the presence the GG and AG genotypes can elicit effective immune response. This may prevent the development of complicated malaria. rs8177400 didn't influence the risk of $P$. falciparum infection in the Pakistani population. It cannot be excluded that the rare variant AA, not observed in this study might have association with complicated malaria and P. falciparum infection. However, this study provides a new potential risk factor for malaria in the Pakistani population. Present findings suggested rs 8177400 polymorphism of TIRAP gene as a candidate gene that may affect the susceptibility of malaria.

Considering the functional importance of rs8177400, this study analyzed its association with the susceptibility and clinical outcomes of malaria upon Plasmodium exposure. This is the first study which investigated the association of rs8177400 with malaria. This study needs to be extended to determine the levels of pro-inflammatory cytokines in the presence of various genotypes of rs8177400 upon Plasmodium exposure. This will clarify the immunogenetic response of host upon Plasmodium exposure. Present findings remained inconclusive due to small sample size and single ethnic population. However, association of rs8177400 polymorphism with malaria, mild malaria and $P$. vivax infection warrant its inclusion in future studies, involving other ethnic populations with large sample size and meta-analysis.

\section{CONCLUSION}

rs8177400 polymorphism of the TIRAP gene was found associated with susceptibility of malaria, mild malaria and $P$. vivax infection. Exposure of $P$. vivax may develop mild malaria symptoms in AG carriers of the Pakistani population.

\section{ACKNOWLEDGEMENT}

We are thankful to Higher Education Commission Pakistan for providing the funds for completion of this research activity. The research work was presented in oral presentation in The $1^{\text {st }}$ International conference on emerging trends in Zoology (8-9 December 2017) held at University of Sargodha, Sargodha, Pakistan. It was also presented in oral presentation in $6^{\text {th }}$ International Conference on Education (15-17 March 2018) held at University of Education, Lahore, Pakistan.

\section{Statement of conflict of interest}

The authors declare that they have no conflict of interest.

\section{REFERENCES}

Armant, M.A. and Fenton, M.J., 2002. Toll-like receptors: A family of pattern-recognition receptors in mammals. Genom. Biol., 3: 3011. http://doi. org/10.1186/gb-2002-3-8-reviews301

Baker, A.R., Qiu, F., Randhawa, A.K., Horne, D.J., Adams, M.D., Shey, M., Barnholtz-Sloan, J., Mayanja-Kizza, H., Kaplan, G., Hanekom, W.A. 
and Boom, W.H., 2012. Genetic variation in TLR genes in Ugandan and South African populations and comparison with HapMap data. PLoS One, 7: 47597. https://doi.org/10.1371/journal. pone.0047597

Bland, J.M. and Altman, D.G., 2000. The odds ratio. Br. med. J., 320: 1468. https://doi.org/10.1136/ bmj.320.7247.1468

Castiblanco, J., Varela, D.C., Castaño-Rodríguez, N., Rojas-Villarraga, A., Hincapié, M.E. and Anaya, J.M., 2008. TIRAP (MAL) S180L polymorphism is a common protective factor against developing tuberculosis and systemic lupus erythematosus. Infect. Genet. Evol., 8: 541-544. https://doi. org/10.1016/j.meegid.2008.03.001

Corr, S.C. and O'Neill, L.A., 2009. Genetic variation in Toll-like receptor signalling and the risk of inflammatory and immune diseases. J. Innate Immun., 1: 350-357. https://doi. org $/ 10.1159 / 000200774$

Day, N.P., Hien, T.T., Schollaardt, T., Loc, P.P., Chuong, L.V., Hong Chau, T.T., Hoang Mai, N.T., Phu, N.H., Sinh, D.X., White, N.J. and Ho, M., 1999. The prognostic and pathophysiologic role of pro- and antiinflammatory cytokines in severe malaria. J. Infect. Dis., 180: 1288-1297. https://doi. org $/ 10.1086 / 315016$

Driss, A., Hibbert, J.M., Wilson, N.O., Iqbal, S.A., Adamkiewicz, T.V. and Stiles, J.K., 2011. Genetic polymorphisms linked to susceptibility to malaria. Malaria J., 10: 271. https://doi.org/10.1186/14752875-10-271

Esposito, S., Molteni, C.G., Zampiero, A., Baggi, E., Lavizzari, A., Semino, M., Daleno, C., Groppo, M., Scala, A., Terranova, L. and Miozzo, M., 2012. Role of polymorphisms of toll-like receptor (TLR) 4, TLR9, toll-interleukin 1 receptor domain containing adaptor protein (TIRAP) and FCGR2A genes in malaria susceptibility and severity in Burundian children. Malaria J., 11: 196. https:// doi.org/10.1186/1475-2875-11-196

Fitzgerald, K.A., Palsson-McDermott, E.M., Bowie, A.G., Jefferies, C.A., Mansell, A.S., Brady, G., Brint, E., Dunne, A., Gray, P., Harte, M.T. and McMurray, D., 2001. Mal (MyD88-adapter-like) is required for Toll-like receptor-4 signal transduction. Nature, 413: 78. https://doi.org/10.1038/35092578

George, J., Kubarenko, A.V., Rautanen, A., Mills, T.C., Colak, E., Kempf, T., Hill, A.V., Nieters, A. and Weber, A.N., 2010. MyD88 adaptor-like D96N is a naturally occurring loss-of-function variant of TIRAP. J. Immunol., 184: 3025-3032. https://doi. org/10.4049/jimmunol.0901156

Gowda, D.C., 2007. TLR-mediated cell signaling by malaria GPIs. Trends Parasitol., 23: 596-604. https://doi.org/10.1016/j.pt.2007.09.003

Hato, T. and Dagher, P.C., 2015. How the innate immune system senses trouble and causes trouble. Clin. J. Am. Soc. Nephrol., 10: 1459-1469. https:// doi.org/10.2215/CJN.04680514

Hawn, T.R., Dunstan, S.J., Thwaites, G.E., Simmons, C.P., Thuong, N.T., Lan, N.T.N., Quy, H.T., Chau, T.T.H., Hieu, N.T., Rodrigues, S. and Janer, M., 2006. A polymorphism in Toll-interleukin 1 receptor domain containing adaptor protein is associated with susceptibility to meningeal tuberculosis. J. Infect. Dis., 194: 1127-1134. https:// doi.org/10.1086/507907

Horng, T., Barton, G.M. and Medzhitov, R., 2001. TIRAP: An adapter molecule in the Toll signaling pathway. Nat. Immunol., 2: 835. https://doi. org/10.1038/ni0901-835

Jain, V., Armah, H.B., Tongren, J.E., Ned, R.M., Wilson, N.O., Crawford, S., Joel, P.K., Singh, M.P., Nagpal, A.C., Dash, A.P. and Udhayakumar, V., 2008. Plasma IP-10, apoptotic and angiogenic factors associated with fatal cerebral malaria in India. Malaria J., 7: 83. https://doi.org/10.1186/14752875-7-83

Kagan, J.C. and Medzhitov, R., 2006. Phosphoinositidemediated adaptor recruitment controls Toll-like receptor signaling. Cell, 125: 943-955. https://doi. org/10.1016/j.cell.2006.03.047

Khattak, A.A., Venkatesan, M., Nadeem, M.F., Satti, H.S., Yaqoob, A., Strauss, K., Khatoon, L., Malik, S.A. and Plowe, C.V., 2013. Prevalence and distribution of human Plasmodium infection in Pakistan. Malaria J., 12: 297. https://doi. org/10.1186/1475-2875-12-297

Khor, C.C., Chapman, S.J., Vannberg, F.O., Dunne, A., Murphy, C., Ling, E.Y., Frodsham, A.J., Walley, A.J., Kyrieleis, O., Khan, A. and Aucan, C., 2007. A malfunctional variant is associated with protection against invasive pneumococcal disease, bacteremia, malaria and tuberculosis. Nat. Genet., 39: 523-528. https://doi.org/10.1038/ng1976

Krishnegowda, G., Hajjar, A.M., Zhu, J., Douglass, E.J., Uematsu,S.,Akira, S., Woods,A.S. and Gowda, D.C., 2005. Induction of proinflammatory responses in macrophages by the glycosylphosphatidylinositols of Plasmodium falciparum: cell signaling receptors, glycosylphosphatidylinositol (GPI) structural requirement, and regulation of GPI activity. J. biol. Chem., 280: 8606-8616. https://doi.org/10.1074/ 
jbc.M413541200

Nagpal, K., Plantinga, T.S., Wong, J., Monks, B.G., Gay, N.J., Netea, M.G., Fitzgerald, K.A. and Golenbock, D.T., 2009. A TIR domain variant of MyD88 adapter-like (Mal)/TIRAP results in loss of MyD88 binding and reduced TLR2/TLR4 signaling. J. biol. Chem., 284: 25742-25748. https://doi.org/10.1074/ jbc.M109.014886

Nejentsev, S., Thye, T., Szeszko, J.S., Stevens, H., Balabanova, Y., Chinbuah, A.M., Hibberd, M., Van de Vosse, E., Alisjahbana, B., van Crevel, R. and Ottenhoff, T.H., 2008. Analysis of association of the TIRAP (MAL) S180L variant and tuberculosis in three populations. Nat. Genet., 40: 261-262. https://doi.org/10.1038/ng0308-261

O’Neill, L.A., Dunne, A., Edjeback, M., Gray, P., Jefferies, C. and Wietek, C., 2003. Mal and MyD88: Adapter proteins involved in signal transduction by Toll-like receptors. J. Endotox. Res., 9: 55-59. https://doi.org/10.1177/09680519030090010701

Onyishi, G.C., Aguzie, I.O.N., Nwani, C.D., Obiezue, R.N.N. and Okoye, I.C., 2018. Malaria-vector dynamics in a tropical urban metropolis, Nigeria. Pakistan J. Zool., 50: 1035-1041. http://dx.doi. org/10.17582/journal.pjz/2018.50.3.1035.1041

Panda, A.K., Das, B.K., Panda, A., Tripathy, R., Pattnaik, S.S., Mahto, H., Pied, S., Pathak, S., Sharma, S. and Ravindran, B., 2016. Heterozygous mutants of TIRAP (S180L) polymorphism protect adult patients with Plasmodium falciparum infection against severe disease and mortality. Infect. Genet. Evol., 43: 146-150. https://doi.org/10.1016/j. meegid.2016.04.035

Pandey, N., Chauhan, A. and Jain, N., 2018. TLR4 polymorphisms and expression in solid cancers. Mol. Diagn. Ther, 22: 683-702. https://doi. org/10.1007/s40291-018-0361-9

Rani, A., Nawaz, S.K., Irfan, S., Arshad, M., Bashir, R. and Shaheen, N., 2017. Role of MyD88-adaptorlike gene polymorphism rs8177374 in modulation of malaria severity in the Pakistani population. Braz. J. Infect. Dis., 21: 418-423. https://doi. org/10.1016/j.bjid.2017.04.002

Sun, T., Holowka, T., Song, Y., Zierow, S., Leng, L., Chen, Y., Xiong, H., Griffith, J., Nouraie, M., Thuma, P.E. and Lolis, E., 2012. A Plasmodiumencoded cytokine suppresses T-cell immunity during malaria. Proc. natl. Acad. Sci., 109: 21172126. https://doi.org/10.1073/pnas.1206573109

Vogel, S.N., Fitzgerald, K.A. and Fenton, M.J., 2003. TLRs: Differential adapter utilization by tolllike receptors mediates TLR-specific patterns of gene expression. Mol. Interv., 3: 466. https://doi. org/10.1124/mi.3.8.466

WHO, 2018. World malaria report, 2018. Avialable at: https://www.who.int/malaria/publications/worldmalaria-report-2018/en/

Wurfel, M.M., Gordon, A.C., Holden, T.D., Radella, F., Strout, J., Kajikawa, O., Ruzinski, J.T., Rona, G., Black, R.A., Stratton, S. and Jarvik, G.P., 2008. Toll-like receptor 1 polymorphisms affect innate immune responses and outcomes in sepsis. Am. J. Respir. Crit. Care Med., 178: 710-720. https://doi. org/10.1164/rccm.200803-462OC

Zakeri, S., Pirahmadi, S., Mehrizi, A.A. and Djadid, N.D., 2011. Genetic variation of TLR-4, TLR-9 and TIRAP genes in Iranian malaria patients genetic variation of TLR-4, TLR-9 and TIRAP genes in Iranian malaria patients. Malaria J., 10: 77. https:// doi.org/10.1186/1475-2875-10-77

Zhang, Y.X., Xue, Y., Zhao, M.Y., Wang, H.J., Li, J.C., Liu, J.Y., Li, F.J. and Zhou, J.M., 2011. Association of TIRAP(MAL) gene polymorhisms with susceptibility to tuberculosis in a Chinese population. Genet. Mol. Res., 10: 7-15. https://doi. org/10.4238/vol10-1 gmr980 